\title{
On the road to Agenda 2030 together in a complex alliance of Swedish public authorities
}

\author{
Klas Palm ${ }^{1}$ (D) Johan Lilja ${ }^{2}$ \\ Received: 18 October 2019 / Accepted: 30 September 2020 / Published online: 13 October 2020 \\ (c) The Author(s) 2020
}

\begin{abstract}
This article describes cooperation between authorities and universities in order to increase innovation capacity and thereby achieve change in performance and execution for better contribution to a sustainable future. Through action research, the authors have developed new knowledge about dialogical organisational development as a method for increasing innovation capacity. The paper recognises that administrative and adaptive leadership must work together effectively if organisations are to function properly and that the complexity cannot be controlled with complicated systems; adaptation is more important than fixing administrative structures. There is a need for a dynamic relationship between the formal and the informal in organisations-between top-down administrative forces and complex, adaptive and emergent forces. The study also shows that there is a need for a wider range and simultaneous use of management models adapted to different contexts and needs.
\end{abstract}

Keywords Sustainable development · Innovation management · Entanglement · Complexity $\cdot$ Leadership $\cdot$ Bureaucracy

\section{Introduction}

The UN Agenda 2030 with its Sustainable Development Goals (SDGs) is universal. All countries are expected to implement the agenda at both the national and international level. The SDGs constitute a unique and challenged goal for socially, economically and ecologically sustainable development in the world. This requires a restructuring of the way society behaves. Public organisations need to be responsive, agile and renew their delivery. The sustainability challenges create challenges that are sometimes called wicked problems as it is difficult to see what happens in the system when trying to solve the problems. By solving

Klas Palm

klas.palm@angstrom.uu.se

Johan Lilja

johan.lilja@miun.se

1 Department of Engineering Sciences, Industrial Engineering and Management, Uppsala University, Box 534, 75121 Uppsala, Sweden

2 Department of Quality Management and Mechanical Engineering, Mid Sweden University, 83125 Östersund, Sweden 
one problem, one can create another. There is a need for new forms of problem solving given that clashes between wicked problems and traditional problem-solving systems often arise (Weber and Khademian 2008). Many public agencies today are not equipped for these changes.

The multilateral Organisation for Economic Co-operation and Development (OECD) has found through analysis that the public sector faces economic, social and environmental challenges and that this requires new ways of thinking about government and how it works (OECD 2014). The OECD confirms that innovation has a central role to play in supporting countries to navigate this landscape. However, public agencies seem to have difficulties coping with more radical development needs (Hartley 2005; Stacey and Griffin 2006; Aagaard 2011). Public agencies seem to have a culture and structure for incremental development but lack the culture and structures for innovations (Wihlman 2014; Palm et al. 2014). The OECD (2014) argues that public agencies in many countries are approaching the limit of what they are able to achieve using existing processes and service delivery systems. Uhl-Bien and Marion (2009) state that 'in today's environment, the vast majority of formal organisations are organised around bureaucratic principles, and bureaucracy provides the context for the bulk of leadership theorising in organisational studies' (p. 632). Further, Bushe (2019, p. 1) stresses' that conventional ideas about leadership are not adequate for responding to today's complex organisational challenges'. Albury (2011), Brorström (2015) and Wihlman (2014) argue that it is not enough to develop ongoing processes but that public agencies also need more innovative development to meet the challenges. Mew management models are needed to drive the development needed in public agencies to be able to come up with innovative solutions so the agencies can help achieve the goals of Agenda 2030.

A movement that has more recently come to reshape how many practitioners lead and facilitate organisational change where there is a big need for innovation and many different actors need to be involved given the complex challenges is Dialogic Organization Development (DOD). Bushe and Marshak (2015) describe DOD as a method that fosters change by encouraging disruption through new organisational conversations and narratives.

The research behind this article wants to increase the understanding of DOD as a method for promoting innovation capacity in public agencies, which then can help to create good conditions for developing the activities of public agencies and the ability to contribute to the objectives of Agenda 2030. In order to contribute to this purpose, the paper is focused on two related research questions.

RQ1: How can DOD contribute to increasing the innovation capacity among public agencies in a manner that leads to a developed ability to contribute to the achievement of the objectives of Agenda 2030?

RQ2: Which are the dominant enablers for DOD's ability to contribute to increased innovation capacity?

\section{Theory}

Kaivo-oja (2011) states that 'today it is important to understand that innovation is no longer optional, but is instead a necessary activity in every competitive industry or in the service market' (p. 4). Brown and Osborn (2013) argue that it is important to differentiate between incremental, i.e., continuous change, and innovative change. They 
believe that innovation is not simply a normative word to connote beneficial change in public policy or services, but is rather a distinctive category of discontinuous change.

Palm and Algehed (2017) identifies that one of the most important factors for achieving a good environment for innovation in public agencies is the opportunity for networking; that employees with different backgrounds and experiences are given the opportunity to meet internally within organisations and to meet between different organisations. This reasoning is in line with Stoker (2006), who believes that one way to increase public management's ability to deliver well in society is to work through networked governance and open up for a wider range of participants to take part in the organisations' development process. Stoker (Ibid.) also argues that the challenge is to find new ways to collaborate. Uhl-Bien and Marion (2009) argue in a similar way and introduce the concept of entanglement. Entanglement recognises that administrative and adaptive leadership must work together effectively if organisations are to function properly; therefore, entanglement refers to a dynamic relationship between the formal, top-down, administrative forces and the informal, complexly adaptive emergent forces in organisations (cf. Thomas et al. 2005).

Argyris (1964) argued that organisational change processes are difficult to implement due to a lack of trust as employees do not feel sufficiently confident. Brown and Osborne (2013) in addition to the National Council for Innovation and Quality in the Public Sector at the Swedish Government (2013) emphasise in the same view that an important and central perspective for creating an enabling environment for innovation in public agencies is trust. One key method of establishing networks and achieving trust is placing focus on the dialogue in the innovation processes. The theories behind DOD do exactly that. The dialogue is at the centre of the development process (Bushe and Marshak 2015). DOD relies on two important intellectual movements, one of which is the science of complexity. The other one is interpretivist social science. As shown in Table 1, the premises of Dialogic OD lead to a different way of thinking about the basic building blocks of organisation development in comparison to the traditional Diagnostic OD. With that said, Bushe and Marshak (2015) point out that 'the Diagnostic Mindset continues today through widespread interest in such things as discovering best practices, benchmarking against world-class organisations, collecting the "right" data and continual searches for the singular causes of some problematic situations that can be fixed by applying analysis and expertise' (p. 13). However, when related to the complexity

Table 1 Diagnostic and dialogic mindsets (ideal types). From Bushe and Marshak (2015)

\begin{tabular}{lll}
\hline Diagnostic OD & & Dialogic OD \\
\hline $\begin{array}{l}\text { Positivism } \\
\text { Objective reality }\end{array}$ & Ontology & $\begin{array}{l}\text { Interpretive, constructionist } \\
\text { Social reality }\end{array}$ \\
$\begin{array}{l}\text { Open systems } \\
\text { Behaviour and results }\end{array}$ & Organisations are & Dialogic networks \\
Planned & Emphasis on & Discourse and generativity \\
Episodic & Change is & Emergent \\
More developmental & & Continuous and iterative \\
Stay apart at the margins & & More transformational \\
Partner with & Consultants & Are immersed with \\
Hierarchical & & Part of \\
Start at top, work down & Change processes & Heterarchical \\
\hline
\end{tabular}


leadership guidelines, as seen in Table 1, it becomes evident that Dialogic OD would be the better match if it were to lead in complex contexts.

The DOD consists of three core change processes. These three processes are: (1) A disruption in ongoing social construction of reality by stimulating and engaging in new ways that can lead to more complex reorganisation. (2) A change process that creates space to highlight one or more new core narratives in the process. (3) Generation of new images that provide new and compelling alternatives for thinking and acting (Bushe and Marshak 2015). These three core change processes are applied in different ways in a spectrum of methods such as Open Space, Visual Explorer and World Café, Bushe (2013). However, one of the most intensively researched and applied practices associated with Dialogic OD is Appreciative Inquiry (AI). In its most practical construction, Cooperrider and Whitney (2005), describe AI as 'a form of organisational study that searches for the best in people, their organisations, and the world around them' (p. 8). In a commonly applied form, Appreciative Inquiry asks organisation members to participate in an iterative development process called the '4-D' model or cycle including the four phases of Discover, Dream, Design and Destiny as seen in Fig. 1. It starts with selecting a topic in focus for the process: affirmative topic choice. The affirmative topic choice is then followed by Discovery of what has been working particularly well in relation to that topic in the past and in the present, and then the participants Dream and envision what it might be like if 'the best of what is' occurred more frequently. Based on their images of what can be, participants are asked to Design things and processes that work particularly well, and finally in Destiny, follow up and implement their desired designs and changes. For further details about Appreciative Inquiry, see, e.g. Cooperrider et al. (2008).

However, the entire DOD methodology and the 4-D Cycle may also need to be elucidated from a different theoretical perspective. Namely, the fact that innovations have to be more than mere ideas and, i.e. that innovations are new ideas brought into implementation

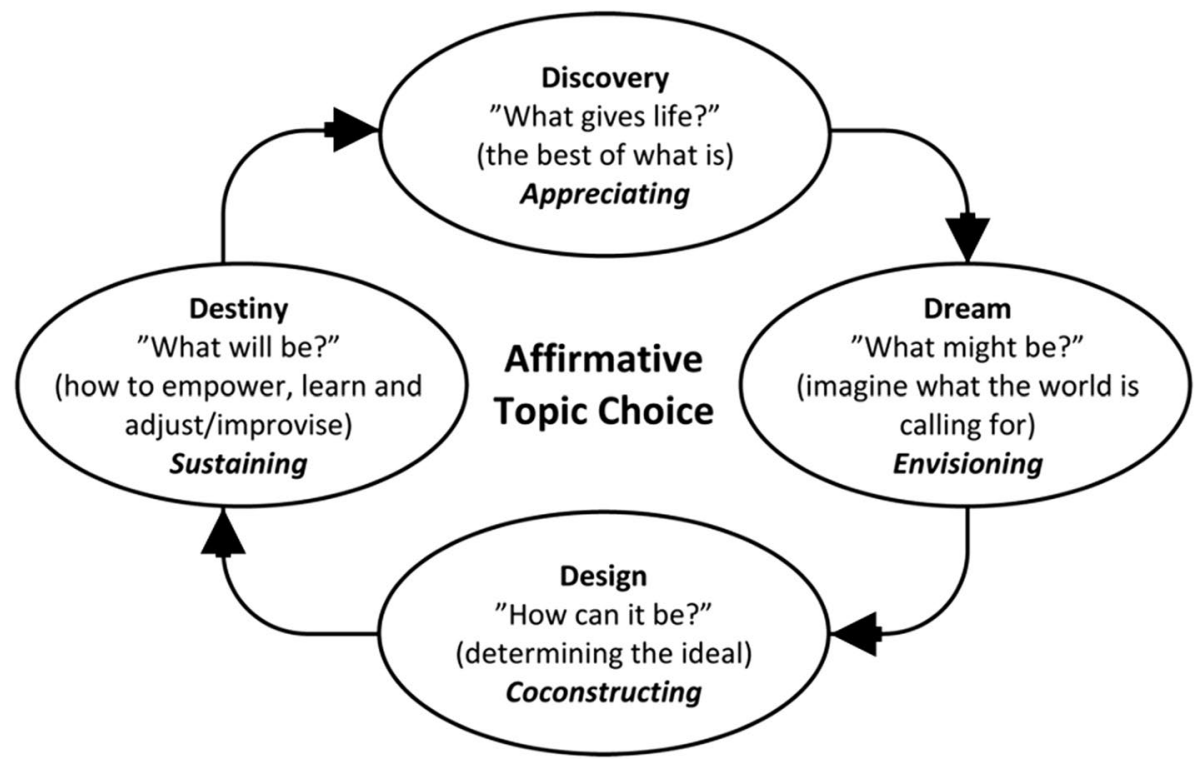

Fig. 1 The 4-D cycle of appreciative inquiry with the four phases of discovery, dream, design and destiny (From Cooperrider et al. 2008) 
(e.g. Moore and Hartly 2008; Tidd et al. 2005). Further, Somech and Drach-Zahavy (2013) describe that it is practically possible to view the innovation process as consisting of only two parts, one idea generating phase and one idea implementing phase and that an innovation has not emerged until the innovation process has gone through both phases.

Furthermore, Weber and Khademian (2008) and Norström et al. (2020) emphasise the importance of working in networking processes to deal with wicked problems and in processes that are expected to contribute to sustainable development. Nordstrom et al. (Ibid.) believe that there is a need for co-production in research that will contribute to change for a sustainable future. Co-production both between fields of science but not least between academia and other actors in social development, such as public authorities. Nordström et al. (Ibid.) Write: 'Co-production promises to address the complex nature of contemporary sustainability challenges better than more traditional scientific approaches' (p. 1) It may therefore be of interest to see how academia and practitioners can work together to contribute to development towards a sustainable future. A theory of action research thus becomes relevant. Reason and Bradbury (2008) argue that action research nearly always begins with the question "How can we improve the situation"? Furthermore, Reason and Bradbury (Ibid.) argue that the core element in action research is dialogue. The dialogue is the primary constructive force. In this dialogue, the researcher is not a passive observer who observes what is happening. The action researcher investigates reality in order to transform it (Fals Borda 1979). It can also be described as using social practice as a source of new understanding (Kemmis et al. 2003). Stringer (2013) posits that action research may violate conventional research methods by not splitting up the relationship between the researcher and the researched objects in a classical way. However, Stringer (Ibid.) further claims that action research has a higher degree of democratic structure with a humanistic approach and supports the participants in the research process to increase their understanding of what is being researched and their own situation. Action research generally helps participants in the research process solve their own problems. Chevalier and Buckles (2013) write that action research today is included as an 'important method in work-based professional development courses and often includes interdisciplinary dialogue' (p. 1). Those perspectives have been particularly important and relevant in the action research initiative underlying this paper.

\section{Method}

The research questions in this study are of such a nature that they are suitable to be answered by a qualitative research method. Therefore, the study was conducted using a qualitative method. The study was conducted with a deductive approach. The study is based on the theory of DOD to test what DOD can mean in the context of public agencies working with the aim to create good conditions for authorities to contribute to the objectives of Agenda 2030. The approach was inspired by Bryman (2012, p. 387) pointing out that it is entirely possible to analyse theory and carry out research efforts through a deductive approach through qualitative data. To answer the research questions, the study also drew from empirical data from a case study. The case was made up of the project Innovation Lab 2030. Project Innovation Lab 2030 was formed and implemented by applying DOD theory with the primary aim of increasing the innovation capacity of three particular 
authorities, so as to increase their ability to contribute to the achievement of the objectives of Agenda 2030.

\subsection{The case}

The Swedish Government decided in 2016 that Sweden should be a leader in the implementation of Agenda 2030, both in implementing the agenda nationally and in contributing to the global implementation of the agenda. The Swedish government controls the authorities by means of regulation letters and instructions. However, in general, the government has chosen not to communicate or concretise the meaning of the high Agenda 2030 ambitions in either the regulatory letter or the instructions (except for a very short list of authorities, namely the authorities that naturally work with environmental issues like the Swedish Environmental Protection Agency and the Agency for Marine and Water Management). The result is that there are weak incentives for the authorities to make strategic decisions and to adapt their operations so that these clearly correspond to increasing the ability to achieve the goals of Agenda 2030. By not developing incentives for contribution to the objectives of Agenda 2030, the management has not developed the activities of the authorities in that direction. Nevertheless, after the government proclaimed its high ambition, the vast majority of the Swedish authorities began at varying degrees to work with their own role. Many authorities began to talk about the need to work in new ways, to be innovative in order to deal with the need for change of what the authorities are doing and how they work. The feeling among many civil servants was that the tools provided by the agency's management did not provide efficient solutions any longer.

Over 50 directors-general for Swedish authorities, signed a letter in 2017 and 2018 stating that their respective authority wants to contribute to the Sustainable Development Goals. However, what this letter of intent has led to regarding changes in the authorities' actions and decisions is uncertain. The authorities' transition work in order to make a clear contribution to a sustainable development of society has on the whole more been driven by committed civil servants than on the basis of clear directives from the organisations' management. As part of this movement came, civil servants at the Swedish International Development Cooperation Agency (Sida), The Swedish Energy Agency and the Swedish Art Council together with three universities (Uppsala University, Mid Sweden University and Malmö University) and one research institute (RISE) to initiate a project where these three authorities and the universities worked together in order to increase the three authorities' innovation capacity. This to develop new means for achieving the objectives of Agenda 2030. The innovation project was called 'Innovation Lab 2030'. The three governmental authorities involved expressed development needs in order to respond to the Swedish government's decision that Sweden should be a leader in the implementation of Agenda 2030. Different individuals at the entailed authorities identified different needs for new methods of working. However, a table of expressed dominant needs is presented in Table 2.

The three universities and the institute have contributed with knowledge and methods to facilitate development towards these needs. Early on, the need to develop new solutions was identified and the project has therefore had the objective of developing higher innovation capacity. Innovation Lab 2030 has not focused on any specific SDG target, but has aimed to increase the general capacity of the participating authorities to change their activities so that the authorities in turn will increase the ability to contribute to the fulfilment of different goals. The project was carried out for 24 months from November 2016 to November 2018. See Fig. 2. The project had a total cost of approximately 200,000 $€$ and has been 
Table 2 By civil servants at the involved authorities who expressed needs for new ways of working in order to increase capacity for contribution to the fulfilment of the objectives of Agenda 2030

Developed infrastructure for dialogue with government offices for how governance, follow up and division of work around Agenda 2030 should be carried out

A joint analysis capacity to highlight target conflicts and analyse the context for work with Agenda 2030

Reporting system on how agencies are strategically and executively working with sustainability

Developed inter-agency networking related to the authorities' international work

A common lab for agencies to experiment and work on execution strategies and business development

Development of attitudes and behaviour internally (both new ways of thinking and acting)

Better understanding of the sustainability dynamics in private sector

New ways of involving the local community; children and young people, in sustainable restructuring

financed by the core authorities and Sweden's governmental innovation agency, Vinnova, which contributed just over 50 per cent of the cost.

The project has strived to reach the project goal through two methodological blocks: (1) competence development initiatives through seminars and workshops and (2) to conduct experimental development projects within authorities with a design-inspired methodology. Two experimental development projects have been run, one with the aim of developing an already existing network consisting of a bigger group of Swedish authorities working with the development of their ability to respond to Agenda 2030 (The Swedish Authorities for Sustainable Development Network). The other experimental project has the aim of developing an innovative capacity in work plan development within the Arts Council. The design methodology was carried out through six workshop events spread over 12 months from April 2017 to March 2018.

Within the management method 'competence development through seminars and workshops,' innovation capacity has been developed in a series of approximately 20 seminars and workshops between February 2017 and September 2018. These seminars and workshops have been conducted internally within the three core authorities as well as in a broader form when several governmental authorities are invited in so that representatives of up to 50 authorities have been involved. Seminaries and workshops have lasted between 1 and $4 \mathrm{~h}$ each. Seminars and workshops have been carried out on the following themes:

\begin{tabular}{|c|c|c|c|c|c|}
\hline \multirow{4}{*}{\begin{tabular}{|l} 
Swedish \\
government \\
decides that \\
Sweden \\
should be a \\
leader in the \\
implement- \\
tation of \\
Agenda 2030
\end{tabular}} & \multirow{4}{*}{$\begin{array}{l}\text { Innovation } \\
\text { Lab } 2030 \\
\text { begins }\end{array}$} & \multicolumn{4}{|c|}{ Approximately 20 seminars and workshop } \\
\hline & & & & \multirow{2}{*}{\multicolumn{2}{|c|}{$\begin{array}{l}\text { Appre- } \\
\text { ciative } \\
\text { Inquiry } \\
\text { workshop }\end{array}$}} \\
\hline & & & & & \\
\hline & & & \multicolumn{3}{|c|}{$\begin{array}{l}\text { Two experimental development } \\
\text { projects }\end{array}$} \\
\hline & 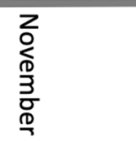 & \multirow{2}{*}{ 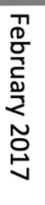 } & \multirow[t]{2}{*}{$\begin{array}{l}\stackrel{D}{0} \\
\stackrel{0}{ٍ} \\
\text { 음 }\end{array}$} & \multirow{2}{*}{ 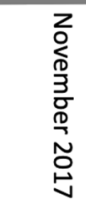 } & \multirow[t]{2}{*}{$\begin{array}{l}3 \\
\stackrel{3}{3} \\
\frac{3}{3} \\
\text { 궁 }\end{array}$} \\
\hline & స్요 & & & & \\
\hline
\end{tabular}

Fig. 2 Timeline for Innovation Lab 2030 
co-creation, service design, innovation management, appreciative inquiry, system thinking, change management, the law's prerequisites for public sector innovation, communication and organisational learning. Both methodologies have been based on a general idea of cocreation and exchange of experiences between the participants. The seminars and workshops have been taking between 1 and $4 \mathrm{~h}$.

One of the most appreciated and vital interventions during Innovation Lab 2030 turned out to be the Appreciative Inquiry workshop conducted on the 17th of November 2017. The workshop involved about 130 participants from around 50 authorities. The workshop design was based upon a DOD Mindset. The core question of the workshop was 'how do we, as a community of 50 authorities, move from intent to action on Agenda 2030?'. Given the complexity of the matter, the workshop was designed to encourage and enable more communication, relations, interaction, ideas and diversity in accordance with 'the leader's job' in complex contexts as seen in Table 1. The process during the workshop was designed as a 4-D cycle in accordance with the Appreciative Inquiry (Fig. 1) with a strong emphasis on design thinking in terms of ideation and prototyping during the design phase. For the discovery phase, the design ended up with three different but related interview guides with affirmative topics to contribute with suggestions on how the authorities can increase innovation capacity to increase their ability of to contribute to the achievement of the objectives of Agenda 2030.

The interview guide consisted of the following three questions:

- How do we integrate sustainability with the inner life of the authorities?

- How do we enable and create a more sustainable society though our official mandate as authorities?

- How do we reach new sustainable progress via collaboration and innovative partnerships?

As a result of the workshop, the authorities identified the root causes of success for each of the three affirmative topics based on shared experiences and stories. The workshop also resulted in the co-creation of 16 prototypes concerning how to actually start acting and reaching progress in response to the three affirmative topics. Presentations of the 16 prototypes, captured in 2-min videos, turned out to be key stimuli and communications material for the following steps during Innovation Lab 2030.

\subsection{Data collection}

The research has been carried out through participatory action research. The authors have had an active role in the implementation of the Innovation Lab 2030 project. Palm has been the project leader for the project and Lilja has been responsible for the implementation of DOD theory in the project. Between one and three persons from each of the three core authorities, together with a representative from the institute and one from each of the three universities (including the authors) constituted a project-management group. Data have been collected through three techniques. First, documentation from the Appreciative Inquiry workshop was collected and constituted a source to answer RQ 1. Secondly, in November 2018, a concluding conversation was carried out within the project-management group which, during one afternoon, discussed the two research questions. Third, participative observations and spontaneous dialogue during the implementation of the project have been conducted by the authors at workshops and seminars. Within this third data collection 
technique the authors have interacted with approximately 400 representatives, primarily from the three core authorities, but also for representatives of approximately 50 authorities that have been involved in the project's workshops and seminars.

\subsection{Analytical method}

A three-step analysis was used. In the first step, adequate observations and our own perceived results and factors were combined with collected opinions and information from the respondents. This data constituted a basis for the most significant results and enablers. In the second step, this most significant data was sorted and clustered. Some categories of results and enablers were identified. Consequently, a number of categories of results and enablers arose.

\section{Findings and analysis}

The findings are complemented by a number of illustrative quotes from respondents. Quotes that exemplify the statements form the basis for the identified factors. The quotes are shown in italics below.

\subsection{Findings related to RQ 1}

To answer RQ 1, we report what the DOD-driven project Innovation Lab 2030 has contributed to increase the innovation capacity aimed at increasing the ability of public authorities to contribute to the achievement of agenda 2030. First, the results of the Appreciative Inquiry workshop on the basis of the three affirmative topics are presented.

Topic 1: How do we integrate sustainability with the inner life of the authorities? The answers from the working groups in the workshop were to develop clear integration of Agenda 2030 into the governance of the authorities. The various sustainability goals are perceived as "floating around for themselves", not related to steering documents for the authorities. A working group during the workshop proposed a joint office for the work and coordination of the authorities around Agenda 2030. This should be supplemented by a coordination body reporting on how the work with Agenda 2030 develops. Furthermore, it was proposed to create an individual "Agenda 2030 compass". After each working day, employees could then reflect on how their own work has been carried out in relation to Agenda 2030. Another idea that emerged in the workshop was to work with global common justice systems. Shared experience between states globally is a prerequisite for global justice and anti-corruption. This means increased work on transparency, confidence-building efforts and responsibility.

Topic 2: How do we enable and create a more sustainable society though our official mandate as authorities? On this issue, new ideas emerged from the workshop's working groups. One group suggested that government offices should create a "sustainability lab" where authorities can develop their official mandate as public authority so that it contributes more clearly to Agenda 2030. In the lab, they could share ideas and experiences between authorities-both positive experiences as well as failures. Another suggestion was that the authorities should, through their mandate, be able to contribute more clearly to conscious sustainable consumption in society by developing financial 
instruments, information to customers through nudging and boosting and promoting sustainable business models.

Topic 3: How do we reach new sustainable progress via collaboration and innovative partnerships? This question generated a large number of responses from various working groups during the workshop. One idea emphasised by a working group was that a first step should consist of identifying collaboration opportunities between authorities and creating a better overall view of how agencies work with implementing Agenda 2030 in their agencies. It was believed that by getting to know each other's businesses, authorities can achieve higher innovation capacity and better development of the business as a whole. Furthermore, the need for a developed joint analysis capacity was highlighted. By creating a situation analysis for each SDG target, conflict of objectives can be detected and the goals can more easily be achieved. Another important task is also to create detailed images and situation analysis at regional level. Yet another working group identifies that it is important for the authorities to gain a greater understanding of the private sector's needs and conditions, so as to make it easier for authorities to promote sustainable business models. This can be achieved by involving authorities and facilitating various issues and discussions with the private sector. One group noted that the local community, children and young people need to be included and involved in the sustainable transition. This can be done by education and promoting engagement in civil society. Youth councils could advise the government's management groups. Further, ideas were generated in relation to the various authorities' international cooperation. In relation to these ideas, a strengthened governmental collaboration between Swedish authorities was proposed to create an understanding of one another's international components of Agenda 2030.

Second, through interviews in the closing seminar, results of the DOD method have been uncovered. Results that can help increase innovation capacity to raise the ability of public agencies to contribute to the achievement of objectives of Agenda 2030. The participants in the interview stress that the DOD method has contributed to the development of new and positive interaction forms within and between authorities, enabling the development of innovations. This means that DOD has contributed in the form of increased ability to work with interactive meetings.-Before we started this, we sat and planned, now we have to get up and interact and create visual models. The meeting culture has changed.

Both through the practical design work and the competence development efforts, a large part of the authorities' staff has gained insight into alternative, design-driven ways of working with business development. DOD has contributed with increased knowledge about how to drive innovative development processes.-We see that within the organisation, it is okay today to work with trial and error, to test and work in iterative processes. It is okay to take development steps without a deep investigation.

The interviewees also stress that Innovation Lab 2030 has resulted in increased insight into the need to co-operate in order to handle the complex challenges that society is facing. The project has provided insights on opportunities and challenges to cooperation. DOD has contributed an increased capacity to co-create.-The project has contributed to an increased insight that one does not need to have a ready-made concept that one launches when opening one's mouth; the insight has increased that one can interact in the development of new ideas without appearing confused and unclear.

The project has also resulted in increased awareness about how innovation takes place. The result has been that the authorities emphasise the importance of all employees experiencing that everyone is involved in processes for continuous learning and curiosity for business development. DOD has contributed an increased likelihood of employees working 
with curiosity and be in a continuous learning mood.-Curiosity becomes the driving force more than before, when we worked with a focus on problem-solving.

Insight has increased the importance of taking small steps and acting on the basis of where you are today, in order to drive greater cultural changes. It is by changing an everyday practice that one can change the authorities' space for innovation. DOD has contributed with the insight that every day, small changes are a lever for driving a large organisational culture change.-We have many small protocols on how we meet as well as how we are expected to speak and act. By changing these protocols, a little bit at a time, we change the cooperation and development climate.

Thirdly, through participative observation and spontaneous dialogue during the implementation of the project, some additional findings have been observed. The project seems to give greater self-confidence among civil servants about the authorities' ability to restructure their activities. Through the processes, the project has encouraged participants and pointed out possible gains via innovation which are related to a sustainable future. DOD has contributed an increased belief in the viability of restructuring business. - The work within Innovation Lab 2030 creates courage and confidence in our adaptability. It offers confidence for the future.

When the authorities work with business development with a diagnostic approach, the processes tend to have difficulty getting around pre-existing regulations, principles, process models and control systems. Innovation Lab 2030 has resulted in increased insight about the fact that other mental processes are needed for innovation than those used when working with the development of ongoing processes. DOD has contributed with awareness of the difference between exploration and exploitation-It is difficult to get out of deep wheel tracks. The challenge is to juggle three balls; continue to deliver, develop what we already do and be innovative to develop new ways to deliver sustainable solutions.

It is also notable that different departments within the authorities have worked a lot with simplification and flexibility, partly as a result of Innovation Lab 2030. This is especially important in the work of restructuring to achieve the goals of Agenda 2030 when the sustainability challenges to be addressed can be described as wicked problems. A dominant insight that emerged during workshops and at the seminar series is that if the authorities shall succeed in achieving the objectives of Agenda 2030, existing routines may need to be simplified and made more flexible. Existing templates for projects-the need to be developed in order to create more room for flexibility during project implementation, i.e. strategic flexibility. DOD has contributed with a common understanding of the need for adaptive management.-Innovation Lab 2030 has taught us that if you have the goal clear, you can let the ' $\mathrm{HOW}$ ' be developed along the way. It is not only not dangerous, but even good, to develop working methods during the journey.

\subsubsection{Summary of responses to RQ1}

In the empirical material, it has emerged that DOD has contributed to increasing the innovation capacity of the authorities that were part of Innovation Lab 2030. It turns out that DOD can contribute increased innovation capacity by contributing to a dialogue where participants are strengthened by generating new solutions. DOD contributes to a common understanding of the need for adaptive management. DOD also contributes to increased awareness of the difference between exploration and exploitation. DOD creates increased belief in the possibility to restructure business. DOD provides increased capacity to cocreate. DOD offers increased capability for employees to work with curiosity and be in a 
continuous learning mood. On the whole, DOD gives increased knowledge about how to drive innovative development processes.

Through the case Innovation Lab 2030, DOD has also generated proposals for what the authorities can develop in their businesses to increase the achievement of Agenda 2030. These proposals are presented in Table 3.

\subsubsection{Findings related to $R Q 2$}

Through the interviews with the project group at the end of the project, some enablers with influence on the opportunities Innovation Lab 2030 have to reach its goal have been revealed. In these interviews, it has been clear that the opportunity to create leeway for innovation is related to the authority's ability to allow experiments and to maintain a permissive culture. For efficient innovation processes, the fear of making mistakes must be discouraged. An organisation which appreciates development attempts and innovative work-whether or not there are successful results, have greater potential to find the worthwhile deviations from existing process norms. An important enabler for working with DOD is to create leeway for experiments as well as support and encouragement even if it goes wrong. Having leeway to test and to carry out assignments in a different way are important components of taking innovative ideas further. This needs to go hand in hand with a permissive management culture. It is linked to trust-driven leadership.

Another crucial enabler for the DOD process is the knowledge among stakeholders in a DOD process about which mandate one has to implement changes. However, knowledge is not enough; it is also important with a real mandate for those who are involved in the change processes, to drive change beyond merely idea generation. Another aspect of mandate is that it seems to convey a feeling of obtained mandate when the employees perceive that they are part of a larger movement towards a common goal. A key enabler for working with DOD is thus that the participants have a mandate to implement the changes.-The work has been driven by a design-democratic method where the participants in the design processes feel that the power of development lies in their hands. The project has encouraged self-organising networks and self-leadership.

The interviews also show that the dream and the vision of a possible and sustainable future are crucial in determining whether one gets enticing processes and involvement in the innovation work. An important enabler for working with DOD is the early identification of the participants' visions for the future.-You don't want to change if you

Table 3 Ideas generated through the Appreciative Inquiry workshop

Generated proposals for what the authorities can develop in their businesses to increase the achievement of Agenda 2030

\footnotetext{
Influence the government's approach to managing public authorities so that Agenda 2030 is integrated into governance documents

Develop structures for the authorities' own follow up work on Agenda 2030

Strengthen the government's cooperation to integrate international aspects of Agenda 2030 into the authorities and their work

Create a "sustainability lab" where authorities can develop their executive role so that it contributes more clearly to Agenda 2030

Contribute more clearly to a consciously sustainable consumption in society

Increase the capacity for joint analysis

Increase collaboration with different stakeholders in society
} 
don't have an attractive picture of the future. An enticing vision is extremely important for creating change in human systems.

In participative observation and spontaneous dialogue during the implementation of the project, some additional enabling factors were identified. DOD has created conditions for managers and employees at different levels to meet in creative conversations. The structure of the dialogue has been such that the official hierarchies of power have been abandoned and everyone has participated in the development work under the same conditions. It has generated an exchange of ideas across traditional boundaries.

Another important enabler for working with DOD is that someone dares to be a forerunner in implementing new innovative solutions. It turns out that for most authorities, it is not explicitly stated in any instructions or regulations that the authorities should work to reach the objectives of Agenda 2030. It has resulted in the director-general's doubt concerning how to move from words to action. However, it is enough that one director-general goes ahead and begins to act, then other directors-general can change position in how they view their responsibility, their mandate and their way of acting. New interpretation of assignments and mandates then change through practice.-When the first director-general declared that they had a mandate and said that as a directorgeneral, they could take on a mandate to pursue these issues, the idea went from words to action and spread like rings on water to other Directors-General.

The work within Innovation Lab 2030 has to a large extent been affected by the fact that other changes are taking place in how management should be conducted. Several major movements in Swedish administration are part of a larger flow presently going in the same direction-towards flexibility, trust in employees and iterative processes. It finds its footing in the form of new ways of working and new methods of organising. One crucial factor for the implementation of Innovation Lab 2030 is the extent to which it has been possible to see how innovation management relates to these other change processes. An important enabler for working with DOD is to adapt DOD so it is aligned with other current management processes.-We have worked with management paradigms that are highlighted from several different directions. This means that we act in a general development trend that is fully in line with the flexible and designdriven working methods that we have highlighted in Innovation Lab 2030.

One crucial factor for the project's implementation is the balance between junior and senior employees' engagement in the DOD process. With young and new employees, great leeway and many new ideas have come along, but at the same time, it has become extra difficult to get new ideas incorporated into everyday businesses. With senior employees, the innovative height does not become as great, but the implementation of new ideas has been easier. An important enabler for working with DOD is to involve both junior and senior employees in change processes. - It is important to take advantage of existing knowledge and experience at the same time as new ideas and fresh eyes are needed. The balance is very important between new ideas and the utilisation of existing experiences.

Design thinking tools have proven to work well for implementing DOD. An important enabler for working with DOD is to use design thinking as a driver of DOD.-The design process enables a space where we can start navigating ourselves based on our own images and interpretations of overall objectives. We can act more and plan less. It is a joyful way to work. 


\subsubsection{Summary of responses to RQ 2}

The case study has shown some dominant enablers for DOD's ability to contribute to increased innovation capacity in public administration. One enabler is that someone dares to be a forerunner in implementing the methodology. Another enabler is when the organisation creates leeway for experiments, and gives appreciative feedback even if the experiments fail. Is seems like another important enabler is that the participants are working under a mandate to implement changes. Also, an early identification of the participants' vision about a sustainable future enables the DOD process. The DOD also needs to be aligned with other current management processes in the organisation. An unconditional collaboration between employees and managers without traditional power structures has been an important factor in the process. Another success factor has been to involve both junior and senior employees in change processes. Finally, design thinking as a driver of DOD seems to be an enabler for DOD methodology.

\section{Discussion}

Innovation Lab 2030 has meant getting into a bureaucratic system and leading a very complex challenge. The projects have been inside and provoked in a system that is created for structure and fixed routines, while at the same time, it has been necessary to find new solutions to deal with the sustainability challenges. Within several authorities, there was a frustration that the existing system was unable to handle both tasks imposed in regulatory letters and work towards SDG targets. By working with DOD methods, Innovation Lab 2030 has contributed to flexibility, network governance and increased capacity to restructure businesses. In reconnecting to previous research and theory, this study provides a contribution to more empirical studies of complexity leadership in bureaucratic organisational forms. Retrospectively, the paper provides a deeper and more complex understanding of the factors involved in what Uhl-Bien and Marion (2009) refer to as entanglement. One of the interesting conclusions of this study is the importance of entanglement in a dynamic relationship between the formal, top-down, administrative forces and the informal, complexly adaptive emergent forces in organisations. The study recognises that administrative and adaptive leadership must work together effectively if organisations are to function properly. But entanglement also creates complex working conditions, which form the background that allows the project to show that complexity cannot be controlled with complicated systems.

The study also shows that Stoker's (2006) theory about networked governance is useful for increasing the capacity of the authorities. Networked governance within the organisations and between the organisations in order to manage the entailed adjustments are needed to enable authorities to contribute effectively to the goals of Agenda 2030. In one way, this has also indicated that academia is pushed towards more collaboration in order to be truly relevant for the complexity of both emerging and studied phenomena. This is in line with what Norström et al. (2020) describes.

It is also apparent that the case study provides further evidence of the potential power of using what Bushe and Marshak (2015) refer to as dialogic organisational development practices, such as Appreciative Inquiry, in coping with complex contexts and challenges related to the SDGs and Agenda 2030. The Appreciative Inquiry workshop, designed in accordance 
with the Appreciative Inquiry 4D Cycle (see Fig. 1), came to be a core intervention that was perceived as truly generative for the following activities and collaboration.

From a wider perspective, the results may also inspire leaders and people within bureaucratic organisational forms, such as agencies, to develop more of a palette of leadership styles based on DOD more than Diagnostic OD (Bushe and Marshak 2015). Without a DOD-driven mindset, there is obviously a risk that agencies and bureaucratic organisations that face complex contexts will fall back on the existing leadership behaviours and put even more resources into traditional demand-and-control practices of analysis, increasing measurements and control when the context at hand actually demands the opposite. In such a context, proper leadership behaviour is rather to encourage dissent, diversity, experimentation and interaction, as argued by, e.g. Weber and Khademian (2008), Bushe (2019), Palm and Algehed (2017) and Stoker (2006).

Despite the opportunities that DOD offers, DOD seems to have difficulty in taking participants further from idea generation to implementation of innovative solutions. The study behind this article indicates that DOD is good for creating and identifying solutions, but in order to really chisel out and implement new solutions, it may need to be brought in other process elements. DOD's strength lies in what Somech and Drach-Zahavy (2013) describe as the idea generating phase, while its shortcoming lies in the fact that it does not seem to realize them. Therefore, DOD might need to be complemented by other means to move from words to action.

\section{Further research}

As stated previously, entanglement recognises that administrative and adaptive leadership must work together effectively if organisations are to function properly; therefore, entanglement refers to a dynamic relationship between the formal, top-down, administrative forces and the informal, complexly adaptive emergent forces in organisations. Given the results of this study, it is apparent that entanglement will be a phenomenon of interest for future research. At the same time, there is a need to deepen knowledge about how DOD can be developed to strengthen the ability to move from words to action in an innovation process.

Funding Open access funding provided by Uppsala University.

Open Access This article is licensed under a Creative Commons Attribution 4.0 International License, which permits use, sharing, adaptation, distribution and reproduction in any medium or format, as long as you give appropriate credit to the original author(s) and the source, provide a link to the Creative Commons licence, and indicate if changes were made. The images or other third party material in this article are included in the article's Creative Commons licence, unless indicated otherwise in a credit line to the material. If material is not included in the article's Creative Commons licence and your intended use is not permitted by statutory regulation or exceeds the permitted use, you will need to obtain permission directly from the copyright holder. To view a copy of this licence, visit http://creativecommons.org/licenses/by/4.0/.

\section{References}

Aagaard, P. (2011). Organizational ambidexterity: How to be both innovative and efficient in the public sector. Working paper 5/2011, Collaborative Innovation in the Public Sector, March 2011, Roskilde University, Roskilde. 
Albury, D. (2011). Creating the conditions for radical public service innovation. Australian Journal of Public Administration, 70(3), 227-235.

Argyris, C. (1964). T-groups for organizational effectiveness. Harvard Business Review, 42(2), 60-74.

Brorström, S. (2015). Implementing innovative ideas in a city: Good solutions on paper but not in practice? International Journal of Public Sector Management, 28(3), 166-180.

Brown, L., \& Osborne, S. P. (2013). Risk and innovation: Towards a framework for risk governance in public services. Public Management Review, 15(2), 186-208.

Bryman, A. (2012). Social research methods (4th ed.). Oxford: Oxford University Press.

Bushe, G. (2013). Dialogic OD: A theory of practice. OD Practitioner, 45(01), 11-17.

Bushe, G. (2019). Generative leadership. Canadian Journal of Physician Leadership, 5(3), 141-147.

Bushe, G., \& Marshak, R. J. (2015). Dialogic organization development: The theory and practice of transformational change. Oakland, CA: Berrett-Koehler.

Chevalier, J. M., \& Buckles, D. J. (2013). Participatory action research. London: Routledge.

Cooperrider, D. L., \& Whitney, D. K. (2005). Appreciative inquiry: A positive revolution in change. San Francisco, CA: Berrett-Koehler.

Cooperrider, D. L., Whitney, D. K., \& Stavros, J. M. (2008). Appreciative inquiry handbook: For leaders of change (2nd ed.). Brunswick, $\mathrm{OH}$ : Crown Custom Publishing.

Fals Borda, O. (1979). Investigating reality in order to transform it: The Colombian experience. Dialectical Anthropology, 4(1), 33-55.

Hartley, J. (2005). Innovation in governance and public services: Past and present. Public Money \& Management, 25(1), 27-34.

Kaivi-Oja, J. (2011). Futures of innovation systems and systemic innovations systems: Towards better innovation quality with new innovation management tools. Turku: Finland Futures Research Centre, University of Turku.

Kemmis, S., \& Kemmis, R. S. (2003). Making and writing the history of the future together: Exploratory action in participatory action research. In Proceedings of the Congreso Internacional de Educación (Congreso V Nacional y III Internacional).

Moore, M., \& Hartley, J. (2008). Innovations in governance. Public Management Review, 10(1), 3-20.

Norström, A. V., et al. (2020). Principles for knowledge co-production in sustainability research. Nature Sustainability, 3(30), 182-190.

OECD. (2014). Building organisational capacity for public sector innovation. Background paper, presented at the conference on building organisational capacity for public sector innovation. OECD Conference Centre, Paris.

Palm, K., \& Algehed, J. (2017). Exploring enablers of innovative quality development in public administration. International Journal of Quality and Service Sciences, 9(2), 203-217.

Palm, K., Lilja, J., \& Wiklund, H. (2014). The challenge of integrating innovation and quality management practice. Total Quality Management \& Business Excellence, 27(1/2), 1-14.

Reason, P., \& Bradbury, H. (2008). Handbook of action research: Participative inquiry and practice (2nd ed.). London: Sage.

Somech, A., \& Drach-Zahavy, A. (2013). Translating team creativity to innovation implementation the role of team composition and climate for innovation. Journal of Management, 39(3), 684-708.

Stacey, R. D., \& Griffin, D. (2006). Complexity and the experience of managing in public sector organizations. Oxon: Routledge.

Stoker, G. (2006). Public value management: A new narrative for networked governance? The American Review of Public Administration, 36(1), 41-57.

Stringer, E. (2013). Action research. London: Sage.

Swedish Government. (2013). SOU (2013:40). Att tänka nytt för att göra nytta - om perspektivskiften $i$ offentlig verksamhet.The National Council for Innovation and Quality in the Public Sector. Fritzes, Stockholm.

Thomas, C., Kaminska-Labbé, R., \& McKelvey, B. (2005). Managing the MNC and exploitation/exploration dilemma: From static balance to dynamic oscillation. In G. Szulanski, J. Porac, \& Y. Doz (Eds.), Strategy Process, Advances in Strategic Management (Vol. 22, pp. 213-247). Bingley: Emerald Group Publishing Limited.

Tidd, J., Bessant, J., \& Pavitt, K. (2005). Managing innovation: Integrating technological, market and organizational change (3rd ed.). Chichester: Wiley.

Uhl-Bien, M., \& Marion, R. (2009). Complexity leadership in bureaucratic forms of organizing: A meso model. The Leadership Quarterly, 20(4), 631-650.

Wihlman, T. (2014). Innovation in municipal welfare services. Doctoral Thesis, Mälardalen University, Västerås. 
Weber, E. P., \& Khademian, A. M. (2008). Wicked problems, knowledge challenges, and collaborative capacity builders in network settings. Public Administration Review, 68(2), 334-349.

Publisher's Note Springer Nature remains neutral with regard to jurisdictional claims in published maps and institutional affiliations. 